\title{
Qualidade de refeições transportadas em restaurante universitário
}

\author{
Quality of meals transported in university restaurant \\ Calidad de comidas transportadas en restaurante universitario
}

\author{
Sulamita Oliveira Gonzaga \\ ORCID: https://orcid.org/0000-0001-6833-4734 \\ Universidade Federal da Bahia, Brasil \\ E-mail: sulamitagonzaga@gmail.com \\ Carlos Rodrigo Nascimento de Lira \\ ORCID: https://orcid.org/0000-0001-7266-1367 \\ Universidade Federal da Bahia, Brasil \\ E-mail: carlos.rodrigo.n@hotmail.com \\ Maria da Conceição Pereira da Fonseca \\ ORCID: https://orcid.org/0000-0003-0325-7162 \\ Universidade Federal da Bahia, Brasil \\ E-mail: mcfonseca@gmail.com
}

\begin{abstract}
Resumo
A modalidade de refeições transportadas caracteriza-se por uma produção em local diferente de onde será distribuída, neste sentido, incorre em mais etapa com riscos de contaminação. Assim, este estudo teve por objetivo avaliar as condições higienicossanitárias e temperatura na produção e distribuição de refeições transportadas. Então, realizou-se estudo transversal, com abordagem quantitativa em um Restaurante Universitário, e para tal, foi realizado monitoramento de temperatura das refeições nas fases de acondicionamento, no recebimento no local de distribuição e no período de distribuição assim como avaliação das condições higienicossanitárias do veículo de transporte e da unidade de distribuição. A técnica recomendada pela Associação Brasileira das Empresas de Refeições Coletivas foi utilizada para aferição da temperatura e aplicado checklist adaptado para o estudo. Com isso, foi constatado que 100\% das preparações da cadeia aquecida na distribuição estavam com temperatura acima de $60^{\circ} \mathrm{C}$, representando adequação à legislação, porém, o mesmo não pôde ser observado na cadeia refrigerada, pois as preparações apresentaram 100\% de inadequação na distribuição das refeições. Com relação ao nível de adequação das condições higienicossanitárias do veículo de transporte $(79,70 \%)$ e da unidade distribuidora $(83,4 \%)$, os mesmos apresentavam adequadas condições de higiene. De modo geral, os resultados demonstram a adoção das boas práticas de fabricação e adequação parcial do controle no processo de distribuição das refeições transportadas. Para que a unidade possa ofertar preparações da cadeia fria com maior segurança sanitária é necessário rever o processo produtivo, bem como os equipamentos de armazenamento das preparações.
\end{abstract}

Palavras-chave: Refeições transportadas; Alimentação coletiva; Serviço de alimentação.

\begin{abstract}
The mode of transported meals is characterized by production in a place different from where it will be distributed, in this sense, it incurs in more stages with risks of contamination. Thus, this study aimed to evaluate the hygienicsanitary conditions and temperature in the production and distribution of transported meals. Then, a cross-sectional study was carried out, with a quantitative approach in a University Restaurant, and for this, the temperature of the meals was monitored during the packaging phases, on receipt at the distribution site and in the distribution period, as well as an evaluation of the hygienic-sanitary conditions of the transport vehicle and the distribution unit. The technique recommended by the Brazilian Association of Collective Meal Companies was used to measure the temperature and a checklist adapted for the study was applied. Thus, it was found that $100 \%$ of the preparations of the heated chain in the distribution had a temperature above $60^{\circ} \mathrm{C}$, representing compliance with legislation, however, the same could not be observed in the refrigerated chain, as the preparations showed $100 \%$ inadequacy in the distribution of meals. Regarding the level of adequacy of the hygienic-sanitary conditions of the transport vehicle $(79.70 \%)$ and of the distribution unit (83.4\%), they presented adequate hygienic conditions. In general, the results demonstrate the adoption of good manufacturing practices and partial adequacy of control in the distribution process of transported meals. In order for the unit to offer cold chain preparations with greater sanitary safety, it is necessary to review the production process, as well as the preparation storage equipment.
\end{abstract}

Keywords: Transported meals; Collective feeding; Food service. 


\begin{abstract}
Resumen
El modo de transporte de las comidas se caracteriza por la producción en un lugar diferente al que será distribuido, en este sentido, incurre en más etapas con riesgos de contaminación. Así, este estudio tuvo como objetivo evaluar las condiciones higiénico-sanitarias y la temperatura en la producción y distribución de las comidas transportadas. Luego, se realizó un estudio transversal, con enfoque cuantitativo en un Restaurante Universitario, y para ello se monitoreó la temperatura de las comidas durante las fases de empaque, en la recepción en el lugar de distribución y en el período de distribución, así como como evaluación de las condiciones higiénico-sanitarias del vehículo de transporte y de la unidad de distribución. Se utilizó la técnica recomendada por la Asociación Brasileña de Empresas Colectivas de Comidas para medir la temperatura y se aplicó una lista de verificación adaptada para el estudio. Así, se encontró que el $100 \%$ de las preparaciones de la cadena calentada en la distribución tenían una temperatura superior a $60^{\circ} \mathrm{C}$, lo que representa cumplimiento de la legislación, sin embargo, no se pudo observar lo mismo en la cadena refrigerada, ya que las preparaciones mostraron $100 \%$ insuficiencia en la distribución de las comidas. En cuanto al nivel de adecuación de las condiciones higiénicas y sanitarias del vehículo de transporte $(79,70 \%)$ y de la unidad de distribución $(83,4 \%)$, presentaron condiciones de higiene adecuadas. En general, los resultados demuestran la adopción de buenas prácticas de fabricación y adecuación parcial del control en el proceso de distribución de las comidas transportadas. Para que la unidad ofrezca preparaciones de cadena de frío con mayor seguridad sanitaria, es necesario revisar el proceso de producción, así como los equipos de almacenamiento de la preparación.
\end{abstract}

Palabras clave: Comidas transportadas; Alimentación colectiva; Servicios de alimentación.

\title{
1. Introdução
}

O serviço de refeições transportadas é caracterizado pela distância entre o local de produção e de distribuição das preparações, neste caso estão inclusos mais processos de manipulação do alimento, que são a carga, transporte e descarga das preparações. Esse sistema permite o fornecimento de refeições onde não há estrutura adequada para sua produção (Silva Júnior, 2018). Da mesma forma, estas refeições também devem seguir os critérios recomendados pela ciência dos alimentos e da nutrição, ou seja, devem ser nutricionalmente equilibrada, preservando as características sensoriais e atender aos critérios higienicossanitários.

O controle de qualidade das refeições transportadas compreende desde a aquisição da matéria prima até a distribuição das preparações. O consumo de alimentos de qualidade duvidosa e fora dos padrões de qualidades são um dos fatores responsáveis pela ocorrência de surtos de Doenças Transmitidas por Alimentos (DTA) (Marinho et al., 2015). Assim, o controle de temperatura, das condições de higiene das instalações, dos manipuladores e do veículo de transporte pode contribuir para garantia da qualidade e segurança das refeições servidas. Para isso, devem constantemente ser monitoradas e implementadas medidas preventivas e corretivas, de forma a minimizar os riscos de contaminação, melhorando assim a qualidade das refeições servidas (Monteiro et al., 2014).

As DTA se constituem em um sério problema de saúde pública mundial. Algumas são problemas de saúde pública em todas as regiões do globo, outras são mais frequentes em países de baixa e médica renda. Nos registros oficiais emitidos pelos países não há uma separação entre as modalidades de refeições, contudo, as estatísticas favorecem para demonstrar o qual relevante é o monitoramento das condições de higiene envolvendo a produção de refeições, independente da modalidade. Nesta tocante, estima-se que as DTA afetam um em cada 10 indivíduos, e causam cerca de 33 milhões de doentes ao ano (WHO, 2015).

Nos Estados Unidos da América, o Centers for Disease Control and Prevention (CDC) divulgou que em 2015 foram confirmadas 4.598 hospitalizações e 77 mortes relacionadas a patógenos bacterianos e parasitários de origem alimentar. Em 2017, notificaram-se 841 surtos de DTA, resultando em 14.481 doentes, 827 hospitalizações e 20 mortes. As categorias de alimentos mais relacionadas ao surto foram: frutas (521 doentes); frango (487 doentes); carne de porco (376 doentes) (CDC, 2017; CDC, 2019).

Por sua vez, no Brasil os surtos de DTA e os casos das doenças definidas em legislação específica são monitorados pela vigilância epidemiológica das DTA. Assim, de acordo com dados do Sistema de Informação de Agravos de Notificação, de 2007 a 2016 foram registrados 6.632 surtos, 469.482 expostos, 118.104 doentes, 17.186 hospitalizações (14,5\%) e 109 
óbitos $(0,09 \%)$, sendo a maior prevalência encontrada na região sudeste (43,8\%) (Ministério da Saúde, 2016).

$\mathrm{Na}$ tentativa de controlar e/ou evitar tais eventos, a Resolução da Diretoria Colegiada - RDC n²16 determina que o armazenamento e transporte do alimento preparado devam ocorrer em condições de tempo e temperatura que não comprometam sua qualidade higienicossanitária e que a temperatura do alimento preparado deve ser monitorada durante todas as etapas para não incorrer em multiplicação de microrganismos resistentes ao aquecimento (Brasil, 2004; Marinho et al., 2009; ABERC, 2015).

É preciso evidenciar e atentar-se para uma constante adequação do controle de qualidade das refeições transportadas, pois a oferta da mesma está pautada no âmbito de atuação do SUS, na medida em que é realizado um controle e fiscalização de um produto (alimentação) de interesse para a saúde; fiscalização e inspeção de alimentos para consumo humano, abrangendo ainda ações de vigilância sanitária, a qual envolve, dentre outras coisas, o controle de bens de consumo que, diretamente, se relaciona com a saúde envolta em várias etapas (da produção ao consumo); e o controle da prestação de serviços que se relacionam direta ou indiretamente com a saúde (Brasil, 1990).

As Unidades de Alimentação e Nutrição (UAN) que possuem esta modalidade de refeições devem buscar soluções a fim de sanar as inadequações provenientes de procedimentos incorretos tanto dos manipuladores como do funcionamento dos equipamentos, transporte e acondicionamento térmico das preparações. Nesta constante, a adoção das Boas Práticas de Fabricação apresenta-se como uma importante medida que visa à redução de riscos de doenças e de outros agravos, além de ser uma forma para garantir a segurança alimentar, a qual é compreendida pelo acesso universal a alimentação nutricionalmente equilibrada, em quantidade e qualidade suficiente também para garantir a saúde do comensal (Brasil, 1990; Lima et al., 2015). Ante o exposto, este trabalho teve por objetivo avaliar a temperatura das preparações e condições higienicossanitárias dos processos envolvidos na modalidade de refeições transportadas.

\section{Metodologia}

Trata-se de um estudo transversal com abordagem quantitativa, do tipo estudo de caso (Estrela, 2018) realizado em um Restaurante Universitário (RU) na cidade do Salvador-Bahia. A pesquisa foi aprovada pelo Comitê de Ética em Pesquisa da Escola de Nutrição da Universidade Federal da Bahia com o parecer $n^{\circ} 228.318 / 2012$. A coleta de dados foi realizada por 13 dias no mês de janeiro de 2019, com acompanhamento da empresa terceirizada que prestava serviços a uma Instituição de Ensino Superior do município de Salvador.

Para a investigação deste estudo foram consideradas três linhas: 1) monitoramento do tempo e temperatura dos alimentos em diferentes momentos do processo produtivo da refeição transportada; 2) avaliação das condições higienicossanitárias do veículo de transporte; 3) avaliação das condições higienicossanitárias do local de distribuição.

$\mathrm{O}$ monitoramento da temperatura dos alimentos foi realizado utilizando um termômetro calibrado, em haste de aço inoxidável, digital da marca INCOTERM com faixa de medição variando de $-50^{\circ} \mathrm{C}$ a $300^{\circ} \mathrm{C}$, com precisão de $4^{\circ} \mathrm{C}$ e com termômetro a laser da mesma marca com alcance de $-50^{\circ} \mathrm{C}$ a $330^{\circ} \mathrm{C}$. Essa aferição ocorreu em quatro momentos distintos do processo produtivo da refeição transportada: 1) no acondicionamento das preparações nos gastronorms (GN), os quais foram acomodados posteriormente em caixas isotérmicas, realizado na unidade produtora; 2) no recebimento das preparações no local de distribuição; 3) nos balcões de distribuição, no período de distribuição (início, meio e fim, 11:00h, 12:00h e 13:00h, respectivamente); e 4) controle de temperatura dos passtroughs usados para o armazenamento das preparações na unidade de distribuição.

A técnica para aferição da temperatura seguiu o descrito pelo Manual de Boas Práticas de Manipulação de Alimentos da Secretária Municipal da Saúde (São Paulo, 2012) e pela Associação Brasileira das Empresas de Refeições Coletivas (ABERC, 2015). Para avaliar se as temperaturas atendiam ao preconizado, foram utilizados como padrão os valores 
estabelecidos na RDC n²16 (Brasil, 2004) para cadeia aquecida e do Centro de Vigilância Sanitária - CVS n5 do estado de São Paulo (São Paulo, 2013) para cadeia refrigerada e classificada em conforme ou não conforme.

A aferição da temperatura dos equipamentos foi realizada com termômetro a laser, e para tal, foram realizadas três medidas considerando para análise o valor médio. O controle do tempo que o alimento ficou em determinada temperatura foi monitorado junto com a aferição da temperatura. Deste modo, ao final foi possível estimar que determinado GN ficou do envase ao recebimento, em uma faixa de temperatura, por tempo máximo de 6 e 4 horas respectivamente, em temperatura adequada.

Os dados foram tabulados em planilha no Microsoft Excel@ versão 2010 e analisados no software Statistical Package for Social Sciences (SPSS) versão 25.0. Uma análise descritiva (média, desvio padrão, frequência simples e absoluta) foi realizada para identificar a proporção de desvios ou não de temperatura, nas fases de saída, transporte, chegada e distribuição das refeições, seguindo os parâmetros da RDC n²16/2004 e CVS n5/2013.

Já a avaliação das condições higienicossanitárias do veículo de transporte foi realizada antes da saída do mesmo da unidade produtora, a partir da aplicação de checklist adaptado de Cardoso et al. (2010) tomando como base as disposições da RDC n²16, da CVS n ${ }^{\circ} 5$ e das cláusulas do contrato entra a Universidade e a concessionária.

Entre os itens constantes no instrumento, foram observados: condições de transporte e higiene do compartimento de carga, o estado de conservação, tipo de revestimento de material (liso, resistente, impermeável, atóxica, lavável), manuseio de cobertura para proteção da carga, se a cabine do condutor era isolada da parte que continham os alimentos, e se a temperatura dos alimentos estava adequada. Além disso, foi também considerado a questão dos recipientes de transporte das preparações, a higienização e desinfecção do veículo, como também a saúde e condições de higiene do condutor do veículo.

Os itens avaliados do checklist foram os indicados com SIM quando estivesse de acordo a legislação, como NÃO quando não estivesse de acordo ao recomendado e NSA quando algum item não fosse aplicável a realidade da Unidade. Também foi considerada pontuação um para todos os itens. Para o cálculo da pontuação utilizou-se a fórmula de Cardoso et al. (2010):

\section{Escore Obtido $\left(\mathrm{E} 0=\frac{\mathrm{Z} \text { dos pontos Poxitivos } \mathrm{x} 100}{\mathrm{Z} \text { dos pontos Possiveis }-\mathrm{Z} \text { dos pontos dos itens Não Aplicáveis }}\right.$}

Legenda: $\sum$ (soma) dos pontos possíveis (SIM + NÃO + NSA).

Assim, com a pontuação obtida, a unidade pode ser classificada em: $<30 \%$ (crítico); $\geq 30 \%$ e $<50 \%$ (insatisfatório); $\geq 50$ e $<70 \%$ (regular); $\geq 70 \%$ e $<90 \%$ (bom); $\geq 90 \%$ (excelente). Além da avaliação diária também foi obtido a média que condensou as avaliações por módulos de cada checklist, além da média do escore geral.

A avaliação das condições higienicossanitárias do ponto de distribuição foi realizada no refeitório antes, durante e após a distribuição das refeições por intermédio de checklist próprio. O instrumento aplicado diariamente foi construído a partir dos parâmetros estabelecidos no contrato entre a concessionária e a Universidade, contemplando itens relacionados aos: aspectos de higienização e organização do refeitório e do balcão de distribuição; recepção das refeições e pré-distribuição; distribuição; fluxo de atendimento aos comensais; higienização dos equipamentos, dos utensílios de distribuição, de panelas e do ambiente; condições de saúde e de higiene dos manipuladores. Os itens também foram avaliados e classificados conforme proposta de Cardoso et al. (2010) descritos anteriormente. 


\section{Resultados e Discussão}

Avaliação da temperatura das preparações no envase, recepção e distribuição

O cardápio da unidade, previamente definido em contrato era composto por nove itens: entrada (duas saladas cruas), acompanhamento (arroz e feijão), guarnição, prato principal, opção ovolactovegetariana, bebida não alcoólica e sobremesa. O preparo de uma parte dos itens quentes era iniciado na madrugada e quando finalizado eram armazenados em GN e mantidos em passtroungh quente para manutenção da temperatura, contudo, não havia informação acerca do horário de finalização e a temperatura em que foi colocado nos GN. Já o horário de finalização das saladas cruas era entre 08h30min e 09h00min.

Do total de 1.400 refeições produzidas para o almoço, 200 eram transportadas para um ponto de distribuição. O tempo médio de deslocamento do local de produção ao de distribuição foi de 21 minutos com distância de 5,2 quilômetros.

$\mathrm{Na}$ Tabela 1 é possível constatar que todas as preparações da cadeia aquecida obtiveram resultados adequados perante RDC n $n^{\circ} 216 / 2004$, com média de temperatura acima de $60^{\circ} \mathrm{C}$ no acondicionamento nas caixas hotbox no momento de saída e de recepção no ponto de distribuição. Já nas preparações da cadeia refrigerada foi encontrada média de temperatura acima do recomendado, tanto na saída quanto na recepção das preparações.

Tabela 1 - Frequência relativa, média e desvio padrão da temperatura dos alimentos na saída e chegada das refeições transportadas. Salvador, Bahia, 2019.

\begin{tabular}{|c|c|c|c|c|c|c|}
\hline \multirow{2}{*}{ Elementos do cardápio } & \multicolumn{3}{|c|}{ Cadeia Aquecida (Saída) } & \multicolumn{3}{|c|}{ Cadeia Aquecida (Recepção) } \\
\hline & $<60^{\circ} \mathrm{C}(\%)$ & $\geq 60^{\circ} \mathrm{C}(\%)$ & Média/DV & $<60^{\circ} \mathrm{C}(\%)$ & $\geq 60^{\circ} \mathrm{C}(\%)$ & Média/DV \\
\hline Arroz & 0,00 & 100,00 & $82,51( \pm 9,39)$ & 5,88 & 94,12 & $78,62( \pm 9,83)$ \\
\hline Feijão & 0,00 & 100,00 & $83,17( \pm 8,21)$ & 0,00 & 100,00 & $80,47( \pm 7,21)$ \\
\hline Guarnição & 0,00 & 100,00 & $81,68( \pm 13,20)$ & 15,00 & 85,00 & $74,95( \pm 12,14)$ \\
\hline Prato principal & 0,00 & 100,00 & $80,34( \pm 8,37)$ & 4,00 & 96,00 & $75,70( \pm 7,54)$ \\
\hline $\begin{array}{l}\text { Opção } \\
\text { ovolactovegetariana }\end{array}$ & 0,00 & 100,00 & $79,90( \pm 7,98)$ & 8,00 & 92,00 & $70,02( \pm 7,25)$ \\
\hline \multirow{2}{*}{ Elementos do cardápio } & \multicolumn{3}{|c|}{ Cadeia Refrigerada (Saída) } & \multicolumn{3}{|c|}{ Cadeia Refrigerada (Recepção) } \\
\hline & $>10^{\circ} \mathrm{C}(\%)$ & $\leq 10^{\circ} \mathrm{C}(\%)$ & Média/DV & $>10^{\circ} \mathrm{C}(\%)$ & $\leq 10^{\circ} \mathrm{C}(\%)$ & Média/DV \\
\hline Salada 1 & 100,00 & 0,00 & $24,59( \pm 2,97)$ & 100,00 & 0,00 & $25,09( \pm 2,28)$ \\
\hline Salada 2 & 100,00 & 0,00 & $22,15( \pm 5,49)$ & 100,00 & 0,00 & $22,09( \pm 5,36)$ \\
\hline
\end{tabular}

Legenda: $\mathrm{DV}=$ desvio padrão; ${ }^{\circ} \mathrm{C}=$ graus célsius. Fonte: Autores.

O período de distribuição das refeições ocorreu por três horas (Tabela 2). Observa-se que todas as temperaturas aferidas da cadeia aquecida estavam com temperatura acima de $60^{\circ} \mathrm{C}$, no entanto, todas as preparações da cadeia refrigerada, no caso as saladas cruas, estavam acima de $10^{\circ} \mathrm{C}$, o que demonstra não conformidade com o estabelecido pelas legislações (Brasil, 2004; São Paulo, 2013). 
Tabela 2 - Frequência relativa, média e desvio padrão da temperatura dos alimentos na distribuição das refeições transportadas. Salvador, Bahia, 2019.

\begin{tabular}{|c|c|c|c|}
\hline \multirow{2}{*}{ Elementos do cardápio } & \multicolumn{3}{|c|}{ Cadeia Aquecida } \\
\hline & $<60^{\circ} \mathrm{C}$ graus célsius $(\%)$ & $\geq 60^{\circ} \mathrm{C}$ graus célsius $(\%)$ & Média/Desvio padrão \\
\hline Arroz & 13,56 & 86,44 & $71,68( \pm 11,14)$ \\
\hline Feijão & 0,00 & 100,00 & $88,72( \pm 9,82)$ \\
\hline Guarnição & 8,47 & 91,53 & $76,04( \pm 13,46)$ \\
\hline Prato principal & 6,78 & 93,22 & $74,44( \pm 13,23)$ \\
\hline Opcão ovolactovegetariana & 15,25 & 84,75 & $73,83( \pm 14,84)$ \\
\hline \multirow{2}{*}{ Elementos do cardápio } & \multicolumn{3}{|c|}{ Cadeia Refrigerada } \\
\hline & $>10^{\circ} \mathrm{C}(\%)$ & $\leq 10^{\circ} \mathrm{C}(\%)$ & Média/DV \\
\hline Salada 1 & 93,22 & 6,78 & $18,26( \pm 5,95)$ \\
\hline Salada 2 & 91,53 & 8,47 & $16,08( \pm 5,78)$ \\
\hline
\end{tabular}

Fonte: Autores.

De acordo com a RDC n²16 (Brasil, 2004) e a CVS n5 (São Paulo, 2013), as preparações quentes devem estar na distribuição com, no mínimo, $60^{\circ} \mathrm{C}$ por, no máximo, 6 horas, e abaixo desta temperatura, por no máximo 1 hora, necessitando que os alimentos sejam desprezados quando não atenderem a tais critérios, contudo, neste estudo ao não obter informação do horário de finalização das preparações quentes, houve limitação em fazer a relação do binômio tempo-temperatura de tais preparações. Estes achados aproximam-se dos de Gonzaga et al. (2019) que ao avaliarem a temperatura de refeições transportadas para universitários na etapa do acondicionamento, constataram que $100 \%$ das preparações da cadeia aquecida atendiam à legislação.

O fato das refeições transportadas possuírem mais etapas de manipulação, consequentemente possui maior risco de contaminação (Silva Júnior, 2018). Portanto, desvios de temperatura que contribuam para permanência dos alimentos por mais tempo na zona de perigo $\left(10^{\circ} \mathrm{C}\right.$ a $\left.60^{\circ} \mathrm{C}\right)$, aumentam o risco de proliferação de microrganismos, favorecendo maior probabilidade para ocorrência de toxinfecções alimentares (São Paulo, 2013). Neste sentido, é dever, enquanto empresas, que tanto a contratante quanto a contratada adotem medidas que excluam ao máximo as possibilidades de ocorrência de uma DTA, tendo em vista que também é de sua responsabilidade a promoção da saúde a partir de um de seus condicionantes que é a alimentação (Brasil, 1990).

Embora a maior parte dos itens do cardápio da cadeia aquecida na etapa de saída, recepção e distribuição estivessem acima de $60^{\circ} \mathrm{C}$, vale ressaltar que $8,47 \%$ da guarnição (por exemplo, macarrão, purê de batata, farofa) na recepção e na distribuição; assim como 13,56\% do arroz; e 15,25\% da opção ovolactovegetariana (base das preparações eram compostos por farináceos e proteína vegetal ou animal) estavam em desacordo com a legislação. Dados semelhantes foram encontrados por Correa et al. (2017), que identificaram adequação de temperatura dos alimentos pós-cocção em $66,6 \%$ dos itens avaliados e menores valores de temperatura para a guarnição e prato principal. Já Monteiro et al. (2014), ao analisarem 21 restaurantes, observaram que apenas três encontravam-se adequados quanto à temperatura dos alimentos quentes.

Uma justificativa para tais desvios observados na UAN em estudo está pautada na técnica de preparo ou na baixa atividade de água que eles apresentam, neste caso, esses alimentos são mais susceptíveis às perdas de temperatura, podendo favorecer o crescimento de alguns microrganismos, como por exemplo, o Bacillus cereus (Silva Júnior, 2018).

Neste estudo análises microbiológicas não foram realizadas, desta forma não é possível afirmar ocorrência de proliferação bacteriana nas preparações, contudo, sabe-se que a temperatura mínima para crescimento de Bacillus cereus oscila entre $4^{\circ} \mathrm{C}$ e $5^{\circ} \mathrm{C}$, e máxima, entre $48^{\circ} \mathrm{C}$ e $50^{\circ} \mathrm{C}$ (Silva Júnior, 2018).

Assim, ao entender que a produção e distribuição de refeições aos estudantes de uma instituição pública federal faz parte da produção de insumos, então se constitui em parte integrante do Sistema Único de Saúde (SUS), logo, devem prezar 
pela garantia da qualidade higienicossanitária e nutricional ao ofertar estas refeições, para que desta forma estejam contribuindo para a garantia de saúde (Brasil, 1990).

Durante a distribuição das saladas cruas na UAN, embora na saída e na recepção 100\% destas preparações estivessem acima $10^{\circ} \mathrm{C}$, observou-se redução da temperatura destes alimentos durante as três horas de distribuição, o que pode ser justificado pelo acondicionamento de uma parte do lote no refrigerador da unidade de distribuição. As legislações determinam que os alimentos frios com temperatura entre $10^{\circ} \mathrm{C}$ e $21^{\circ} \mathrm{C}$, podem permanecer na distribuição por no máximo duas horas após o preparo. Diante disso, a distribuição destes alimentos apresentou-se como a mais perigosa para a saúde dos comensais, pois se apresentou totalmente em desacordo com as recomendações ao observar que estes alimentos eram produzidos muito antes de iniciar a etapa de distribuição e ficavam em temperatura de risco por longo tempo, comprometendo a qualidade higienicossanitária do produto. Ainda, observou-se que fatores como o armazenamento inadequado e ausência de equipamento de resfriamento rápido contribuíram para perda de temperatura.

Constata-se desta forma que os maiores e mais graves desvios de temperatura observados na Unidade referem-se à cadeia refrigerada. No Brasil, hortaliças são predominantemente comercializadas in natura, logo, sua carga microbiológica ao chegar à UAN é alta, agrava-se ainda o fato de serem consumidas cruas, neste caso, eficazes medidas de higiene e controle de temperatura são as principais medidas adotadas para torná-lo seguro ao consumo humano. Contudo, inúmeros estudos mostram que estas preparações em UAN são os principais problemas para a segurança alimentar, tanto no que se refere à qualidade microbiológica (Knychala et al., 2010; Luz et al., 2017; Rustichelli et al., 2017; Santos et al., 2019) quanto em questões de temperatura (Penedo et al., 2015; Silva et al., 2016; Barros et al., 2019).

Estes achados tornam-se mais preocupantes na medida em que são evidenciados quais são os principais alimentos envolvidos em surtos alimentares, que são exatamente aqueles que não passaram por tratamento térmico antes de ser servido. O CDC (2019) identificou que dos 25 surtos que ocorreram em vários estados, muitos surtos estavam ligados a uma única categoria de alimentos, sendo os principais deles as frutas (10 surtos); culturas vegetais em linha, como verduras (5 surtos); laticínios (2 surtos), dentre outros. E no Brasil, no período de 2007 a 2016, hortaliças $(0,8 \%)$ e frutas, produtos de frutas e similares $(0,6 \%)$ foram reportados como alimentos incriminados (MS, 2016).

Não menos importante está o controle de análise da temperatura dos equipamentos em que são armazenadas as preparações, na medida em que se estiverem descalibrados e/ou quebrados, são fortes contribuintes para os desvios de temperatura, neste estudo, os balcões de distribuição estavam, na maioria das vezes, adequados ao recomendado pela legislação. O balcão de distribuição aquecido e refrigerado apresentaram, respectivamente, $64,41 \%$ e $91,67 \%$ de adequação, porém o refrigerador (50\%) demonstrou necessidade de manutenção corretiva (Tabela 3).

Tabela 3 - Temperatura dos equipamentos utilizados no armazenamento e distribuição de refeições transportadas. Salvador, Bahia, 2019.

\begin{tabular}{|c|c|c|c|}
\hline \multirow{2}{*}{ Equipamentos } & \multicolumn{3}{|c|}{ Cadeia Aquecida } \\
\hline & $<80^{\circ} \mathrm{C}(\%)$ & $\geq 80^{\circ} \mathrm{C}(\%)$ & Média/DV \\
\hline Balcão de distribuição & 35,59 & 64,41 & $69,00( \pm 20,01)$ \\
\hline Passtrough quente & 23,26 & 76,74 & $62,02( \pm 17,50)$ \\
\hline \multirow{2}{*}{ Equipamentos } & \multicolumn{3}{|c|}{ Cadeia Refrigerada } \\
\hline & $>10^{\circ} \mathrm{C}(\%)$ & $\leq 10^{\circ} \mathrm{C}(\%)$ & Média/DV \\
\hline Balcão de distribuição & 8,33 & 91,67 & $13,98( \pm 3,11)$ \\
\hline Refrigerador de salada & 50,00 & 50,00 & $10,14( \pm 2,21)$ \\
\hline
\end{tabular}

Legenda: ${ }^{\circ} \mathrm{C}=$ graus célsius; $\mathrm{DV}=$ desvio padrão. Fonte: Autores. 
No que tange a avaliação das condições de higiene do transporte e distribuição das refeições transportadas a Tabela 4 apresenta que o escore geral foi classificado como bom $(79,7 \%)$, tendo em vista que quase todos os módulos contribuíram para esta classificação, com exceção ao bloco seis, que se refere à saúde e condições de higiene do condutor (64,9\% - regular), demonstrando assim a necessidade de maiores intervenções.

O condutor do veículo é considerado manipulador indireto de alimentos, assim sendo, todo o controle exigido para os manipuladores diretos deve ser aplicado ao condutor (Brasil, 2004). Ao avaliar os itens contidos no módulo seis foi identificado que os principais contribuintes para este resultado foi o fato de o motorista possuir barba, adorno e unhas com esmalte, além disso, era frequente a conversa durante a carga e descarga das preparações.

Tabela 4 - Avaliação das condições higienicossanitárias do veículo de transporte de refeições transportadas. Salvador, Bahia, 2019.

\begin{tabular}{l|ccc|c|c}
\hline \multirow{2}{*}{\multicolumn{1}{c|}{ Módulo }} & \multicolumn{3}{c|}{ Semana } & \multirow{2}{*}{ Escore Global } & \multirow{2}{*}{ Classificação } \\
\cline { 2 - 4 } & $\mathbf{1}$ & $\mathbf{2}$ & $\mathbf{3}$ & 75 & Bom \\
\hline 1-Carga e descarga. & 75 & 75 & 75 & 83,3 & Bom \\
2-Controle das refeições. & 83,3 & 83,3 & 83,3 & 100 & Excelente \\
3-Utensílios e equipamentos. & 100 & 100 & 100 & 100 & Bom \\
4-Veiculo de transporte. & 74 & 80 & 70 & 74,7 & Bom \\
5-Limpeza e desinfecção do veículo & 80 & 80 & 80 & 80 & Regular \\
de transporte. & 68 & 62,2 & 64,4 & 64,9 & Bom \\
6-Saúde e condições do condutor do & & 80 & 78,8 & 79,7 & \\
veiculo. & \multicolumn{1}{c}{ Escore Global } & & & & \\
\hline
\end{tabular}

Fonte: Autores.

Ao avaliar as condições de armazenamento e distribuição das refeições transportadas, é possível observar que o escore global obteve classificação excelente (91,6\%), sendo favorecido pelos blocos 01 e do 03 ao 08 (Tabela 5). Ainda assim, havia necessidade de melhoria para alcançar a excelência em todos os blocos analisados, como na etapa da recepção onde o recebimento das preparações deve ocorrer em área protegida, que seja supervisionado por nutricionista, identificação das caixas isotérmicas com o horário do término de preparo e temperatura dos alimentos da cadeia refrigerada (São Paulo, 2013).

Tabela 5 - Escore por bloco e global das condições higienicossanitárias da unidade distribuidora de refeições transportadas. Salvador, Bahia, 2019.

\begin{tabular}{|c|c|c|c|c|c|}
\hline \multirow{2}{*}{ Módulo } & \multicolumn{3}{|c|}{ Semana } & \multirow{2}{*}{$\begin{array}{l}\text { Escore } \\
\text { Global }\end{array}$} & \multirow{2}{*}{ Classificação } \\
\hline & 1 & 2 & 3 & & \\
\hline $\begin{array}{l}\text { 1- Higienização e organização do refeitório e } \\
\text { balcão de distribuição. }\end{array}$ & 97,4 & 95,6 & 82,6 & 91,9 & Excelente \\
\hline 2 - Recepção. & 70,7 & 66,9 & 66,4 & 68 & Regular \\
\hline 3 - Distribuição. & 88,3 & 90 & 81,7 & 86,7 & Bom \\
\hline 4- Fluxos de atendimentos aos comensais. & 100 & 100 & 100 & 100 & Excelente \\
\hline 5-Higienização dos equipamentos. & 100 & 100 & 100 & 100 & Excelente \\
\hline 6 - Higienizações dos utensílios de distribuição. & 100 & 95 & 100 & 98,3 & Excelente \\
\hline 7- Higienizações de panelas. & 100 & 97,14 & 100 & 99 & Excelente \\
\hline 8- Higienizações do ambiente. & 100 & 100 & 100 & 100 & Excelente \\
\hline 9- Comportamento e higiene dos funcionários. & 82 & 80 & 80 & 80,7 & Bom \\
\hline Escore Global & 93,1 & 91,6 & 90 & 91,6 & Excelente \\
\hline
\end{tabular}


Fonte: Autores.

Achados similares foram observados no estudo de Rocha et al. (2010) que avaliaram as condições higienicossanitárias de 17 restaurantes comerciais do tipo self-service e constataram que 70,60\% das unidades estavam em adequação ao preconizado pelas legislações. Sales et al. (2017) também encontraram um nível considerado bom ao avaliarem as condições higienicossanitárias de cinco UAN de universidades no interior do Ceará.

Os achados deste estudo ressaltam a importância do constante controle das condições de higiene e, sobretudo de temperatura do processo produtivo de refeições, independente do sistema, pois são demonstrados em registros oficiais que os locais de maiores ocorrência dos surtos alimentares são os restaurantes. Nos Estados Unidos são atribuídos que 489 surtos $(64 \%)$ e 5.533 doenças associadas a estes suros (44\%) ocorreram em restaurantes e destes, 366 surtos, (48\%) foram em restaurantes de refeições coletivas (CDC, 2019). Já no Brasil, no período de 2007 a 2016 os locais para início de ocorrência dos surtos foram em restaurantes/padarias (16,2\%) (MS, 2016).

\section{Considerações Finais}

Atendendo ao objetivo do estudo, pôde-se verificar que a qualidade das preparações da cadeia aquecida na modalidade de refeições transportadas apresentara maiores níveis de adequação ao que preconizam as legislações em vigor no país. Entretanto, a cadeia refrigerada não obteve resultados satisfatórios, demonstrando maior preocupação, haja vista que em torno de $90 \%$ das preparações no acondicionamento e distribuição estavam com desvios de temperatura. Deste modo é essencial que os responsáveis técnicos pelo serviço busquem medidas emergenciais e eficazes para solucionar este problema.

$\mathrm{Na}$ medida em que são estabelecidos que os principais fatores causais para o comprometimento da saúde com o alimento servido referem-se principalmente as condições de conservação inadequada e nas etapas de manipulação/preparação inadequada, logo, alguns desafios necessitam ser vencidos para que os objetivos com a oferta de refeições em Unidades de Alimentação e Nutrição sejam alcançados.

Alguns destes desafios estão pautados no processo de prevenção, o que cabe de certo modo constante investimento na formação dos responsáveis técnicos das Unidades. Evidencia-se também a necessidade do permanente planejamento, monitoramento, avaliação e revisão da aplicação das normas técnicas. Além do diagnóstico oportuno para uma rápida intervenção, para que desta forma, não incorram em malefícios aos comensais, além de atender ao que determina o Sistema Único de Saúde. Por fim, abordamos como sugestão para trabalhos futuros que investigadores abordem o controle do tempo e temperatura desta modalidade de refeições por um período de tempo maior e em Unidades de Alimentação e Nutrição de outros segmentos que trabalhem com esta modalidade de refeições, como presídios, hospitais, eventos de massa, instituições de longa permanência para idosos, dentre outros.

\section{Referências}

Associação Brasileira das Empresas de Refeições Coletivas (ABERC). (2015). Manual de práticas de elaboração e serviço de refeições para coletividades. (11a ed.).

Brasil. (1990). Lei $\mathrm{n}^{\circ} 8.080,19$ de setembro de 1990, dispõe sobre as condições para a promoção, proteção e recuperação da saúde, a organização e o funcionamento dos serviços correspondentes. Presidência da República. Casa Civil. Diário Oficial da União.

Brasil. (2004). Resolução da Diretoria Colegiada - RDC n²16, 15 de setembro de 2004. Regulamento Técnico de Boas Práticas para Serviços de alimentação. Agência Nacional de Vigilância Sanitária. Diário Oficial da União.

Barros, N. V. A., Oliveira, A. P., Araújo, S. I. F., \& Silva, N. C. (2019). Avaliação da qualidade higiênico-sanitária em restaurantes self-service do município de Picos-PI. Revista Interdisciplinar, 12(2), 53-60.

Cardoso, R. C. V., Góes, J. A. W., Almeida, R. C. C., Almeida, R. C. C., Guimarães, A. G., Barreto, D. L., Silva, S. A., Figueiredo, K. V. N. A., Júnior, P. O. V., Silva, E. O., \& Huttner, L. B. (2010). Programa nacional de alimentação escolar: há segurança na produção de alimentos em escolas de Salvador (Bahia). Revista de Nutrição, 23, 801-11. 
Centers For Disease Control And Prevention (CDC). (2017). Foodborne Diseases Active Surveillance Network (FoodNet): FoodNet 2015 Surveillance Report (Final Data). Atlanta, Georgia: U.S. Department of Health and Human Services, CDC.

Centers For Disease Control And Prevention (CDC). (2019). Surveillance for Foodborne Disease Outbreaks, United States, 2017, Annual Report. Atlanta, Georgia: U.S. Department of Health and Human Services, CD.

Correa, V. G., Queiroz, F., Bonin, E., Fatel, E. C. S., \& Guedes, G. B. (2017). Monitoramento do binômio tempo e temperatura nos processos de produção de alimentos em um restaurante universitário. Brazilian Journal of Food Research, 8(2), 46-56. 10.3895/rebrapa.v8n2.4886

Estrela, C. (2018). Metodologia Científica: Ciência, Ensino, Pesquisa. Editora Artes Médicas.

Gonzaga, S. L., Gonçalves, S. A., Lira, C. R. N., \& Fonseca, M. C. P. (2019). Unidade distribuidora de refeições transportadas: Estudo de caso em universidade baiana. In: Anais do IX Congresso Latino Americano, XV Congresso Brasileiro de Higienistas de Alimentos e VII Encontro do Sistema Brasileiro de Inspeção de Produtos de Origem Animal. Revista Higiene Alimentar, 33(288/289), 408-412. Disponível em: https://www.higienealimentar.com.br/wp-content/uploads/2019/06/Anais-Higienistas-2019_web-2.pdf.

Knychala, M. M., Melo, R. T., Mendonça, E. P., Coelho, L. R., \& Rossi, D. A. (2010). Qualidade microbiológica de vegetais minimamente processados. PUBVET, 4(35).

Uchoa, F. N. M., Lima, M. S., Maia, S. R., dos Santos, A. T., Foschetti, D. A., Cerqueira, G. S., \& Daniele, T. M. da C. (2015). Análise microbiológica da lavagem de mãos em funcionários de uma unidade de alimentação e nutrição de Fortaleza - CE. Revista Intertox-EcoAdvisor de Toxicologia Risco Ambiental e Sociedade, 8(3), 61-69. https://doi.org/10.22280/revintervol8ed3.218

Luz, J. G. G., Barbosa, M. V., Carvalho, A. G., Resende, S. D., Dias, J. V. L., \& Martins, H. R. (2017). Contamination by intestinal parasites in vegetables marketed in an area of Jequitinhonha Valley, Minas Gerais, Brazil. Revista de Nutrição, 30(1), 127-136. https://doi.org/10.1590/1678-98652017000100012

Marinho, C. B., Souza, C. S., \& Ramos, S. A. (2009). Avaliação do binômio tempo-temperatura de refeições transportadas. E-Scientia, 2(1).

Marinho, G. A., Oliveira, G. S., Lima, J. L., Lopes, W. M. A., Nunes, G. A., \& Nunes, M. G. A. (2015). Perfil epidemiológico das Doenças Transmitidas por Alimentos e seus fatores causais na região da Zona da Mata Sul de Pernambuco. UNOPAR Cient Ciênc Biol Saúde, 17(4), 238-43. https://doi.org/10.17921/2447-8938.2015v17n4p\%25p

Ministério Da Saúde. Surtos de Doenças Transmitidas por Alimentos no Brasil. Secretaria de Vigilância em Saúde. Departamento de Vigilância das Doenças Transmissíveis. Coordenação Geral de Doenças Transmissíveis. Unidade de Vigilância das Doenças de Transmissão Hídrica e Alimentar. Junho, 2016. Disponível em: https://portalarquivos.saude.gov.br/images/pdf/2016/junho/08/Apresenta----o-Surtos-DTA-2016.pdf. Acesso em: 28 de abril de 2020.

Monteiro, M. A. M., Ribeiro, R. C., Fernandes, B. D. A., Sousa, J. F. R., \& Santos, L. M. (2014). Controle das temperaturas de armazenamento e de distribuição de alimentos em restaurantes comerciais de uma instituição pública de ensino. Demetra, Alimentação, Nutrição \& Saúde, 9(1), 99-106. DOI 10.12957/demetra.2014.6800

Penedo, A. O., Jesus, R. B., Silva, S. C. F., Monteiro, M. A. M., \& Ribeiro, R. C. (2015). Avaliação das temperaturas dos alimentos durante o preparo e distribuição em restaurantes comerciais de Belo Horizonte - MG. Demetra, Alimentação, Nutrição \& Saúde, 10(2), 429-440. 10.12957/demetra.2015.15317

Rocha, B., Batista, L. D. S., Borges, B. M. A., \& Paiva, A. C. (2010). Avaliação das condições higiênico-sanitárias e da temperatura das refeições servidas em restaurantes comerciais do tipo self-service. Perquirere, 1(7), 30-40.

Rustichelli, B. G., Chaud, D. M. A., Barbosa, A. S., Viana, N. P., Santos, M. S., \& Abreu, E. S. (2017). Qualidade microbiológica de vegetais folhosos minimamente processados de hortifrútis na região metropolitana de São Paulo. Nutrivisa - Revista de Nutrição e Vigilância em Saúde, 4(2).

Sales, N. C. M., Silva, A. M., Castro, J. N., \& Aguiar, N. M. O. (2017). Avaliação das condições higiênico-sanitárias de serviços de alimentação terceirizados em universidades federais no interior do Ceará. In: VIII Congresso Latino-Americano e XIV Congresso Brasileiro de Higienistas de Alimentos. São Paulo: Revista higiene alimentar, 31(266/267), 158-162.

Santos, K. R., Morais, F. L. R., Castro, J. M. V., Araújo, L. K. C., Sousa, N. A., \& Sousa Júnior, S. C. (2019). Detection of parasitic structures in vegetables sold in Parnaíba, Piauí. O mundo da saúde, 43(1), 083-100. 10.15343/0104-7809.20194301083100

São Paulo. (2012). Secretaria Municipal da Saúde. Manual de boas práticas de manipulação de alimentos. Prefeitura do município de São Paulo, 42 p.

São Paulo. (2013). Portaria CVS 5, de 09 de abril de 2013, dispõe sobre o regulamento técnico sobre boas práticas para estabelecimentos comerciais de alimentos e para serviços de alimentação, e o roteiro de inspeção. Secretaria de Estado da Saúde. Coordenadoria de Controle de Doenças. Centro de Vigilância Sanitária. Divisão de Produtos Relacionados à Saúde. Diário Oficial do Estado, publicado em 19 de 04 de 2013, n73, Poder Executivo - Seção I - pág. 32 35 .

Silva, G. A., Silva, L. A., Alves, C. C. M., Costa, T. A. (2016). Temperaturas de expositores de alimentos e qualidade higiênico- sanitária em restaurante selfservice, na cidade de Itapaci - GO. Refacer - Revista Eletrônica da Faculdade de Ceres, 5(2). https://doi.org/10.36607/refacer.v5i2.3363

Silva Júnior, E. A. (2018). Manual de controle higiênico-sanitário em serviços de alimentação. Varela; 2018. 61p.

World Health Organization (WHO). (2015). Estimates of the Global Burden of Foodborne Diseases. https://www.who.int/foodsafety/areas_work/foodbornediseases/ferg_infographics/en/. Acesso em: 28 de abril de 2020. 